\title{
Mimese: sobre processos de conhecimento, representação artística e formação na história da educação.
}

\section{Mimesis: on processes of knowledge, artistic representation and formation in the history of education.}

\author{
Marcus Vinicius Corrêa Carvalho*
}

\begin{abstract}
RESUMO
Proponho neste texto uma análise das relações decisivas, para a cultura ocidental, entre mimese e educação. Em minha perspectiva, esses termos são mesmo indissociáveis no exercício do ato educador, na medida em que, ao longo do desdobramento dos esforços formativos durante a trajetória ocidental nos últimos dois mil anos, o significado polissêmico do termo mimese ultrapassou em muito sua tradução consagrada como "imitação", definindo aspectos cruciais do que se entende como educação.
\end{abstract}

Palavras-chave: Conhecimento. Representação. Artística. Formação. História da Educação.

\begin{abstract}
This text analyses the decisive relations, for western culture, between mimesis and education. I assume these terms are actually indissociable in the performance of the educator's act, at least when one understands that, throughout the unfolding of the formative efforts during the western course in the last thousand years, the polysemic meaning of the term mimesis has greatly overcome its consecrated translation into "imitation", defining crucial aspects of education.

Keywords: Knowledge. Artistic Representation. Formation. History of Education.
\end{abstract}

"Só tem definição aquilo que não tem história".

(Sergio Buarque de Holanda)

* Universidade Federal Fluminense. Niterói, Rio de Janeiro, Brasil. E-mail: marcuscarvalho. uff@gmail.com. https://orcid.org/0000-0003-1473-0912. 
Proponho neste texto uma análise das relações decisivas entre mimese e educação para a cultura ocidental. Suponho que esses termos sejam mesmo indissociáveis no exercício do ato educador, na medida em que o significado polissêmico do termo mimese ultrapassou em muito sua tradução consagrada como "imitação" ao longo do desdobramento dos esforços formativos durante a trajetória ocidental nos últimos dois mil anos.

O convite, portanto, é para refletir sobre como a polissemia do termo mimese - abrangendo noções como imitação, representação e formação - implica questões variadas e complexas nos campos da ética e da estética, as quais são, por seu turno, decisivas para conceber o modo como o ocidente vem tratando as dinâmicas formativas humanas em sua história milenar.

A proposta de uma abordagem de longa duração se sustenta na ideia de que ao acompanhar a operatividade da noção de mimese em diferentes condições de contorno histórico seja possível vislumbrar aspectos de seu impacto em campos como a ética - abrangendo, por exemplo, dimensões políticas nos debates sobre as fronteiras entre público e privado - e como naquele, aparentemente mais evidente, da estética - exemplarmente, nas discussões sobre as expressões formais da arte em seu impacto sobre a sensibilidade humana. Argumento que arbitrar uma abordagem configurada desse modo favorece que sejam tematizados aspectos múltiplos que puseram e ainda põem em tensão questões irredutíveis a uma ou outra dimensão da realidade, dando a ver, ou pelo menos sugerindo, que a complexidade interdependente de rupturas, mudanças, inflexões, limites, dissoluções, continuidades, sobrevivências, permanências e pregnâncias institui um arranjo nada óbvio que permite vislumbrar, ponderar e questionar o ato educador e o exercício formativo como construção e/ou transmissão de crenças, valores, costumes, sociabilidades e conhecimento. Desse modo, pretendo reconhecer parâmetros e critérios, ao mesmo tempo amplos, permeáveis e lúcidos o suficiente para sustentar uma visada crítica razoável e consistente sobre as dinâmicas formativas que engendramos, sem reduzi-las ao exercício instrucional de ensinança como realização exclusivamente técnico-científica, ou mesmo a quaisquer outras dimensões que não considerem sua complexidade de interações interdependentes e contextuais.

Esse tratamento também favorece ponderar sobre a construção de uma cultura que tensionou, invariavelmente, ao longo de sua história - e não raro tornou dicotômica - as relações entre conhecimento e representação artística. Tal distinção contempla, assim, os fundamentos da cultura ocidental que circunscreveu em seu desdobramento multissecular, diferentes âmbitos entre, de um lado, conhecimento, filosofia, saber científico e técnico e, de outro, aquilo que foi sendo designado como poiesis, criação, arte, imitação, representação, entre outros termos. A opção por esse tratamento implica o interesse em eluci- 
dar aspectos cruciais daquilo que delimitou a circunscrição de um e de outro âmbito na história do ocidente que, não é exagero afirmar, resume-se no termo mimesis. Afinal, mimese é definida, tradicionalmente, como aquilo que opõe a representação artística às formas de reflexão teórica. Enfim, mimese e sua tradução latina, imitatio, estiveram no centro da prática artística e da reflexão ocidental por séculos, primeiro, como fundamento do processo criativo, depois, como alvo de crítica e refutação amplas.

Entretanto, conhecimento e representação artística não são dimensões que tenham limites passíveis de distinção evidente ao considerar que ambos interferem um na outro, sendo, sobretudo, discursos sobre o mundo e a realidade, mesmo que, por vezes, assumindo modalidades formais distintas. Nesse sentido, Di Santo argumenta que "[e]m particular, a reavaliação da mimesis no decorrer da última década [...] é quase sempre caracterizada mesmo como uma reavaliação de seu valor cognitivo, reagindo à refutação estruturalista anterior de qualquer

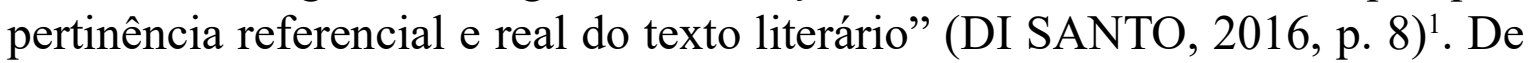
fato, a discussão sobre as implicações cognitivas da mimese remontam a Platão, que fizera do conceito o fundamento de sua ontologia, opondo as dimensões do conhecimento e da arte, negando à mimese poética qualquer possibilidade de favorecer o acesso à verdade. De outro modo, a reavaliação da mimese tende a fazer interagir essas dimensões, no mínimo, arrefecendo seu caráter opositivo.

Nessa medida, levar a sério as relações entre mimese e educação supõe guarda do núcleo vibrante do questionamento ético e estético sobre as implicações da interdependência e da inter-relação entre conhecimento e representação artística para a história da cultura formativa no ocidente. Há, sem dúvida, um sem-número de elementos a ser considerados em tema tão vasto e que move dimensões tão profundas daquilo que impõe, inclusive, as bases da reflexão sobre como se concebeu o propriamente "humano" ao longo da história do ocidente. Importa desenhar um arranjo de elementos que dê a ver a complexidade da problemática implicada para demarcar entrincheiramentos nodais das relações entre mimese e educação que possam auxiliar na percepção de como essa correlação constituiu-se na história ocidental.

A interrogação dos fundamentos e dos pressupostos dessa correlação envolve, por exemplo, perguntar se a recente reavaliação do caráter cognitivo

1 Federico Di Santo destaca o "papel determinante" de Paul Ricoeur para essa reavaliação da mimesis que contradiz as abordagens estruturalistas, então, em voga. Vale acompanhar a abordagem de Ricoeur sobre a mimesis para compreender a centralidade do conceito em sua tese sobre a relação entre tempo e narrativa e dimensionar seu valor na reavaliação da mimese referida por Di Santo. Para dimensionar a força do argumento ricoeuriano, importa consultar o seu Tempo e narrativa em três volumes, sobretudo, a subseção "A tripla mímesis", no capítulo "Tempo e narrativa", do volume um. RICOEUR, 2010. 
da mimese levou em conta os pressupostos mobilizados para considerar a mimese artística como uma teoria da arte em sua pertinência com a realidade. Além disso, de maneira ainda mais ampla, seria apropriado considerar que a estética moderna contaminou a estrutura do pensamento cognitivo e da criação artística com a instituição do conceito de "originalidade" da obra de arte, substancialmente estranho à estética da tradição. Desde o romantismo, requer-se uma provisão de "novidade" em relação à tradição como condição de legitimação e atribuição de valor para a obra de arte. A produção artística vinha assim a justificar-se em base ao que de "novo" e "inédito" teria a contribuir com as obras e os estilos do passado, acompanhando, nessa medida, o pensamento filosófico ou científico. Impor-se-ia, portanto, a repensar os fundamentos implementados pela estética moderna recusando aquela da tradição, que desde a época clássica grega sancionou o paradigma estético da mimese instaurado por Platão e Aristóteles, chegando até aos limiares dos Oitocentos, em uma inflexão que estendeu parcialmente à arte paradigmas próprios ao conhecimento, como os de "originalidade", "inovação", "progresso". Caberia, igualmente, investigar em que proporção a reavaliação do processo cognitivo da mimese se estabelece criticamente em vista da concepção geral de arte na contemporaneidade.

Neste texto, entretanto, o intento é dar a ver condições de contorno que possibilitam relacionar mimese e educação com o interesse de delinear uma circunscrição primária que favoreça futuras incursões de pensadores e historiadores da educação nesta temática vasta e complexa. Deve estar clara a impossibilidade de abranger tal espectro de variáveis no exercício de reflexão deste texto, cujo foco recairá sobre as relações estreitas entre mimesis e imitatio na tradição antiga e renascentista a fim de demarcar elementos basais que possibilitem investigar e ponderar sobre o interesse renovado, moderna e contemporaneamente, no valor heurístico da representação da arte. Interessa, principalmente, uma apresentação da mimese como processo que implica imitação e representação da realidade e, também, relação com modelos artísticos, impactando a formação humana.

Enfim, interessa-me, neste momento, apresentar as referências básicas que permitem o tratamento dos temas e das questões que, gestados na antiguidade, reverberam em problemáticas implicadas na modernidade, principalmente, levando em conta sua irredutibilidade a um tratamento trans-histórico que desconsidere as emergências históricas de sua condição de contorno.

Mimese e educação são arbitradas como "entricheiramentos dinâmicos" que teriam determinado suas feições e operações em diferentes momentos do processo histórico ocidental, delimitando-as como configurações culturais emergentes (ISER, 2001, p. 36). Com isso, indico que a definição de mimese e educação deve ser delimitada por um momento específico no tempo, que as circunscreve em uma situação histórica e cultural própria, acarretando relações 
contextuais, a partir das quais surge uma ampla gama de possibilidades de pensar e definir o que sejam.

Desde essa perspectiva, mimese e educação não deveriam ser confinadas em conceitos que pudessem prescindir de um contexto e/ou de uma circunstancialização histórica em que sua definição tornar-se-ia operatória, fazendo algo emergir, cultivando algo, isto é, gerando probabilidades de desdobramentos processuais em cascata - delas derivadas ou a ela associadas - como manifestações sociais de cultura. Proponho que ambas sejam interpretadas como sistemas emergentes dinâmicos instáveis. Em outras palavras, sugiro que ambas guardam séries de componentes e de variáveis que se conectam em ambientes locais, os quais estabelecem redes de ação em inter-relação e interdependência, fazendo emergir uma cooperação desse conjunto de componentes e variáveis sem que haja uma unidade central que dirija necessariamente esses processos ou os perpetue. Assim, elas deveriam ser analisadas em dinâmica de redes, cuja manifestação ocorreria caoticamente, possibilitando a emergência dinâmica e instável de ordem em determinados contextos históricos e sociais. Portanto, em um sistema relativamente aleatório cujo comportamento qualitativo não seria passível de circunscrição exclusiva a um ou outro campo de saber - fosse ele filosófico, histórico, ou, sociológico, etc. --, torna a dinâmica de seus processos, nesse sentido, indomáveis.

As injunções complexas do tema já se apresentavam no tratamento central que Platão emprestou à mimese poética em seu pensamento. Se no Fedro o fenômeno poético era pensado em sua função didática exercida na cultura helênica, em $A$ república a função educativa da mimese poética foi diretamente relacionada à questão da justiça, imbricando as implicações da formação dos jovens gregos pela tradição oral da transmissão da poesia homérica com as bases teológico-morais da organização da cidade.

No Livro X d'A república, Platão buscou fundamentar metafísica e ,epistemologicamente, a censura de cunho teológico-moral que havia estabelecido anteriormente nos Livros II e III, quando externara essa censura em vista de uma reconstituição dos fundamentos do sistema educacional grego. No Livro $\mathrm{X}$, ele analisou os efeitos psicológicos causados pela contemplação estética, a qual incitaria na alma humana todo tipo de afecção baixa ao obscurecer as prescrições do que a razão compreende como melhor, desviando o reto caminho da moralidade. Platão deixava clara a preocupação com o contexto histórico específico em que a poesia participava do cotidiano grego, manifestando-se no domínio público construído na relação entre poeta e ouvinte como base do sistema educacional.

A atitude de Platão marcava uma contundente inflexão com o pensamento e a religião aos olhos de sua contemporaneidade, posto que os poetas 
gozavam de prestígio público e reputação de sábios, sendo os poemas homéricos, especialmente, considerados entre as principais fontes de conhecimento e de valores morais, fundamentando a visão de homem, de mundo, o modelo de organização social e política, de educação e de ética (LOPES, 2010).

A consideração da mimese nesse contexto não se reduzia aos atributos da poesia aural, antes abrangia toda a expressão artística, compreendida como tekhné. A homologia entre as artes se explicitava, como corrente naquela conjuntura cultural, quando Platão tratava da expressão poética exemplificando-a através de referências à pintura, como se lê em passagens diversas de $A$ república $^{2}$. Note-se que poiein - verbo do qual derivam os termos poesis e poiesis que, intercambiáveis à época, serviam para indiciar o que se traduz atualmente como poesia - indicava o fazer, o fabricar, o construir, independendo do material e/ou dos modos utilizados para tanto. Assim, poiêtês era o termo utilizado para indicar o poeta, mas também, de modo amplo, "aquele que faz, que cria" (GUINSBURG, 2006, p. 377).

A abrangência da mimese foi expressa em sua amplitude nos cinco primeiros capítulos da Poética, quando Aristóteles explicou a atividade mimética, interessado em apresentar a epopéia e a tragédia, temas centrais de sua lição. A epopéia, tragédia, comédia, poesia ditirâmbica, música de cítara e flauta eram todas consideradas mimese, bem como as representações por cores e figuras, ou a partir da voz, além da dança, que mimetizava não apenas caracteres, mas, igualmente, emoções e ações, segundo o Estagirita.

A experiência mimética era tratada mesmo como fundamento da instituição do humano, na medida em que Aristóteles afirmou que: "[...]parece ter havido para a poesia em geral duas causas, causas essas naturais. Uma é que imitar é natural aos homens desde a infância e nisto diferem dos outros animais, pois o homem é o que tem mais capacidade de imitar e é pela imitação que adquire os seus primeiros conhecimentos". A outra, segundo ele, era que "todos sentem prazer em imitar" (ARISTÓTELES, 2007, p. 37-42)

O fazer da palavra oral e escrita tornou-se o modelo de imitação a ser seguido pelas outras técnicas de representação artísticas antigas desde a Poética de Aristóteles. O "fazer" fundamentava em homologia as relações entre a pintura e a poesia desde Simônides de Ceos, sofista grego do século VI a.C., que proferira o aforismo: "a pintura é uma poesia muda; a poesia uma pintura que fala".

2 Ver entre tantas: A república, X, 600e4-601a3, e, 605a8-c4 em GUINSBURG, 2006, e, LOPES, 2010.

3 Sobre as relações entre mimese, educação, ética e estética em Platão e Aristóteles, sugere-se acompanhar também, entre outros: COLE, (1995); HALLIWELL, (2002); BAKTIR, (2003); DI SANTO, (2016). 
Esse aforismo foi repetido por Plutarco e por outros tantos ao longo da história ocidental, tornando-se célebre. Afinal, ele definiu lugar-comum consagrado pela expressão "como pintura, poesia", vt pictura poesis, fixado e difundido a partir da Epistola aos Pisões, ou, Arte poética, de Horácio (HORÁCIO, 1984, p. $109-111)^{4}$.

Mimese como imitatio difere, substancialmente, da imitação de uma ação como supunha Aristóteles na Poética. Ainda que a imitação de homens em ação estivesse no horizonte da tradição latina, a imitatio considerava também a imitação de um texto pelo outro, por exemplo. Assim, a imitatio latina indiciava um processo de produção que articulava lugares-comuns que, extraídos de seus contextos de origem e transportados a outros contextos, permitia que fossem ressignificados (CONTE, 1996; KENNEDY, 1994; KENNEDY, 1999). A imitatio operava lugares-comuns- topoi- isto é, ela processava proposições e fontes de argumento, que poderiam ser ideias, relatos mitológicos ou lugares de origem formando uma rede inter-relacional entre eles, produzindo ativação circular, reinterpretada e repetida, cuja forja impunha uma anterioridade ideativa que estimulava, fazia nascer e alimentava uma vocação, e, ao mesmo tempo, servia como a garantia que legitimava uma autoridade, enquanto o artista atualizava essas categorias míticas que lhe preexistiam.

Nesse sentido, os lugares-comuns tinham por função emprestar legitimidade às práticas artísticas, mas, igualmente, às práticas educativas e sociais, quer dizer, éticas. Imitava-se, portanto, um modelo de inspiração e de autoridade. Em seus primeiros passos, a imitação operava de modo "servil" ou "escolar", até que fossem dominados os fundamentos e as propriedades daquela produção, quando, então, a "imitação servil ou escolar" propiciava a "emulação" desses modelos de autoridade. O conjunto de regramentos técnicos e doutrinários para realizar os construtos em sua produção mimética, sejam eles artísticos ou sociais, conformava a instituição do "decoro" e da "conveniência". O princípio do decoro sustentava o sentido emulativo do processo mimético, dando mais ênfase ao interesse de se igualar ou superar um modelo para filiar-se a uma tradição.

Fundado na dinâmica mimética, decorum - ou convenevolezza -, foi um dos princípios ético-retóricos fundamentais ao pensamento e à arte ocidentais desde a antiguidade. Como preceito regular de adequação e conveniência de meios e fins representacionais, consagrado pela longa tradição da retórica e da poética, o decoro foi orientação pertinente a praticamente todas as manifestações técnico-artísticas da retórica, da poesia, do teatro, da pintura, da escultura, da arquitetura, e que tais, até pelo menos o século XVIII (BASTOS, 2007). Enfim,

4 Sobre o conceito de mimese e sua relação com o topos do vt pictura poesis, consultar, por exemplo: LEE, (1940); SELIGMANN-SILVA, (1998). 
mimese, operando como decoro, foi orientação ética e estética pertinente a toda ação humana.

Do sublime, de Hermógenes, no século II d.C., foi marco emergente da imitatio como processo largamente utilizado por autores latinos e por retores clássicos a fim de caracterizar o procedimento literário de retomada de modelos que fazem parte de uma mesma tradição literária, cujo teor estava na base da literatura latina. O termo imitatio contemplava, especialmente, o caráter emulativo desse recurso, posto que as imitações eram concebidas como forma de rivalizar com os predecessores, ou, como ornamentos que qualificavam a obra ou homenageavam os autores dignos de lembrança (PRATA, 2007, p. 31-32). Segundo Quintiliano, o orador também se utilizava da imitatio. Na Institutio oratoria, ele comentou que a arte oratória seria constituída da imitatio em grande parte e que o orador deveria, além de inventar, imitar seus predecessores: "[d]e fato, assim como inventar foi o principal e continua sendo o mais importante, é útil seguir o que foi bem inventado" (Apud PRATA, 2002, p. 19).

A imitatio não implicava, nessa concepção, em ato mecânico, havendo antes um exercício de inteligência crítica implicado no processo a fim de discernir a qualidade da obra em questão e uma apropriação que não se daria por compreensão apenas das palavras do modelo, mas também de seus propósitos e métodos (RUSSEL, 2001, p. 6). Mimesis, como indicava Dionysius - Pseudo Longino -, "é uma atividade que reproduz o modelo por meio de princípios teóricos". Zelos, o processo de emulação - zelosis em grego - seria, ainda segundo Dionysius, uma "atividade da mente, surgida da admiração por alguma coisa considerada bela" (Apud RUSSEL, 2001, p. 10). Correlacionadas, mimese e emulação teriam a mesma finalidade, complementando-se uma à outra. As ideias de imitatio e aemulatio estariam ligadas em um complexo procedimento criativo, definido pela profundidade do entendimento do objeto de imitação e emulação pelo imitador e por sua capacidade de torná-lo seu. Russel comenta que Horácio atacava seus próprios imitatores como "um bando de escravos", não por condená-los por o terem copiado, o que seria lisonjeiro, mas por o terem feito num tratamento superficial e trivial (RUSSEL, 2001, p. 2). Condenável, portanto, seria uma imitação servil, incapaz de perceber os aspectos cruciais e o interesse daquilo que é imitado tornando-o próprio ao emulador. O processo de imitatio como exercício emulativo impunha uma dinâmica que ultrapassaria as feições de uma cópia do modelo, exigindo engenho e criatividade para marcar os aspectos apropriados e, ao mesmo tempo, seu novo contexto e propósito.

A atualização dinamizada pela imitatio, de acordo com os preceitos mantidos desde a tradição antiga, envolvia dois pontos centrais: o objeto de imitação e aquilo que deveria ser levado em consideração na imitação. Dever-se-ia escolher as boas qualidades abstraídas de vários autores e/ou de várias 
obras, transpondo também as características verbais do modelo escolhido para abranger sua verdadeira significação. A atualização pressuposta no processo criativo humano assim estruturado, entretanto, poderia dar margem a confusões, especialmente, no que tange ao ato de plágio.

Plagium provinha do grego plágios ou plágion, termo que guardava o significado de oblíquo, transversal, tortuoso, ambíguo, astucioso e doloso. No direito romano, plagium significou, posteriormente, sequestro, ocultação, doação, compra e venda de escravo alheio sem autorização do dono, como também ato voluntário de manter em servidão um homem livre. Mantinha-se, portanto, o sentido de ato astucioso e doloso do qual faz parte o logro, uma vez que composto de indução e sedução. Em latim e/ou em grego, preservava-se o sentido comum, guardado ainda no uso atual, daquilo que não é reto, do que não é correto. A associação do ato de plágio ao roubo de textos escritos foi posterior, tendo sido atribuída a Marcus Valerius Martialis, considerado o primeiro a empregar a palavra plagium à atividade poética dos escritores latinos no século I d.C. O procedimento da imitatio, porém, não deve ser confundido com o ato de plágio, estabelecido em Marcial como a apropriação ilícita de escritos de outrem, vergonhosa e desleal; crime de furto cometido às escondidas de forma inescrupulosa. A imitatio, ao contrário, era procedimento aceito e reconhecido pelos escritores antigos que, inclusive, pretendiam deixar explícita a apropriação realizada (PRATA, 2002, p. 19-24).

Exemplar da centralidade da questão da imitatio no Renascimento foi a "controvérsia ciceroniana", uma das querelas mais intensas do século XVI. Ela foi inaugurada no século XV com as polêmicas entre Lorenzo Valla e Poggio Braccilioni, ganhando força, mais tarde, com o debate entre Angelo Poliziano e Paolo Cortesi no início do próximo século, contrapondo interpretações divergentes acerca da prática da imitatio. Pietro Bembo e outros letrados, por um lado, defendiam a imitação exclusiva de Cícero, sendo conhecidos por essa adesão como "ciceronianos simples". De outro lado, os "ciceronianos ecléticos" advogavam a favor de certo ecletismo na adoção de modelos para imitação, ainda que eles também tivessem em Cícero o modelo privilegiado. Para eles, dentre os quais inclui-se Pico della Mirandola, a prática imitativa pressupunha o estudo de modelos diversos que seriam reelaborados conforme as necessidades e convenções retóricas seguidas pelo escritor (MORGANTI, 2017, p. 213).

Petrarca mantinha posição próxima aos ciceronianos ecléticos, nunca tendo defendido Cícero como modelo único de emulação, mesmo o tendo com admiração e predileção por ter adquirido proficiência em letras latinas graças ao orador romano. Na leitura que fizera de De oratore, Petrarca atribuiu pouco peso à relação entre capacidade natural de oradores e a escolha de um único mestre que lhes fossem mais adequados. A atitude de Petrarca relacionar-se- 
-ia a duas passagens de Quintiliano na Institutiones oratoriae. Uma, em que Quintiliano asseverava que aquele capaz de admirar o estilo de Cícero já teria feito grandes progressos na arte retórica. Outra, em que aconselhava ao orador não estabelecer relação de submissão com nenhum modelo particular. Essas asserções somavam-se à recusa petrarquista de empregar o mesmo léxico do modelo, bem como da recusa de uma imitação marcada pela identitas e não pela similaritas, impedindo que não só tomasse Cícero como modelo único, mas também imitasse-o de modo servil. Com isso, apesar da preferência por Cícero, Petrarca recorreu a metáforas tomadas da epístola de Sêneca a Lucílio para definir mais claramente sua proposição sobre a imitatio.

$\mathrm{Na}$ epístola 84, Sêneca aconselhava Lucílio sobre a importância de equilibrar atividades de leitura e de escrita, advertindo-o sobre o valor de praticá-las alternadamente. O ponto central era a reflexão sobre a relação entre a leitura da produção pregressa e de exemplares atuais para abordar a imitação dos grandes modelos literários. Com esse intuito, Sêneca mobilizou quatro metáforas. Primeiro comparando o fazer do poeta à pratica das abelhas na produção do mel. Depois, comparando o processo imitativo na produção letrada ao processo digestivo, alertando que se deveria digerir aquilo que fora lido e convertê-lo em outra coisa, como faz o aparelho digestivo que transforma os alimentos em energia para o corpo. Em seguida ele sustentou que a relação entre os modelos e a obra que os imita deve ser análoga à relação entre pais e filhos. Por fim, na quarta metáfora, ele indicava a relação entre o coro que formava um todo harmônico a partir da composição de diferentes vozes, assim como o processo imitativo literário que comporia algo novo imitando elementos diversos (MORGANTI, 2017, p. 215).

Petrarca destacou e reelaborou duas dessas metáforas para argumentar sobre sua poética da imitação. Ele retomou a imagem da semelhança entre pai e filho para qualificar a relação entre a nova obra e seu modelo, cuja regulação deveria se expressar pela semelhança e não pela identidade 5 . Petrarca utilizou também a imagem da abelha que coleta o material que dá origem ao mel a par-

5 Importa acompanhar os termos de Petrarca: “[...] o imitador deve tomar cuidado para que aquilo que escreve seja semelhante, não igual, e a semelhança deve ser não como aquela entre o original e a cópia, que quanto mais semelhante tanto mais louvável, mas como aquela entre o pai e o filho. Nesses, de fato, ainda que a aparência seja muito diferente, uma certa sombra e aquilo que os pintores chamam de 'ar', e que se revela sobretudo no rosto e nos olhos, produz uma semelhança que faz com que, vendo o filho, rapidamente nos lembremos do pai; ainda que sob um exame mais atento, tudo pareça diferente, há, contudo, ali, algo misterioso, que produz esse efeito. Da mesmo forma, devemos nos precaver de que, se há algo de semelhante, muito haja de diferente, e aquilo que é semelhante esteja de tal modo escondido que não possa ser descoberto exceto por uma tácita investigação do pensamento, de modo que seja possível antes percebê-lo do que descrevê-lo. Portanto, deve-se fazer uso do engenho e das cores de outrem, não das palavras; pois aquela imitação 
tir de flores diversas ${ }^{6}$. Petrarca enfatizou que as abelhas criaram seu produto a partir do acréscimo de um elemento particular e peculiar, sendo ele resultante de transformação que o fizera, assim, inteiramente novo. A tônica da novidade engenhosa na argumentação de Petrarca dá a ver que, mesmo reconhecendo que, por vezes, é inevitável a imitação literal, importa, sobremaneira, como forma superior de imitação a re-elaboração das ideias de outras obras e/ou de outros autores com palavras novas e com rearranjos próprios.

Com as metáforas que Petrarca emprestou de Sêneca indica-se como a relação entre imitatio e aemulatio ultrapassa a significação que restringe a imitação do ato do plágio, do furto e da cópia. Desse modo, é possível vislumbrar que engenho, invenção e crítica fazem parte do processo mimético conforme concebido no medievo e no renascimento, dando a ver que uma dinâmica de formação e de criação não se circunscreveria somente àquilo que na modernidade fundiu-se às noções de progresso e de originalidade instruídas por concepções iluministas e românticas de subjetividade. A visada sobre a cultura do medievo e do renascimento, então, exige levar a sério seus entrincheiramentos dinâmicos próprios no que tange aos processos formativos que não se circunscrevem pelos parâmetros de uma "estética da originalidade" (DI SANTO, 2016, p. 17) sintetizados, exemplarmente, na noção de "gênio original"?.

permanece escondida, essa se mostra, aquela é própria dos poetas, essa dos símios" (PETRARCA apud MORGANTI, 2017, p. 216).

6 Mais uma vez, interessa acompanhar suas palavras: "Segundo dizem, devemos imitar as abelhas que zanzam, e as flores apropriadas para fazer o mel sugam. Em seguida, tudo aquilo que retiram, dispõem e distribuem pelos favos, e como diz nosso Virgílio, 'acumulam o límpido/mel e enchem os alvéolos com doce néctar'. Não é claro o bastante se elas extraem das flores o suco que é, de fato, o mel, ou se transformam aquilo que recolheram naquele sabor, por meio de uma certa mistura e da propriedade de seu espírito. Com efeito, para alguns, elas não possuem a habilidade de fazer o mel, mas de colhê-lo. Dizem que na Índia se encontra mel nas folhas das canas, ou porque o produz o orvalho daquele céu ou porque o produz o doce e muito denso líquido da própria cana. Também nas nossas plantas é possível encontrar, mas de maneira menos evidente e notável, essa mesma essência que o inseto, com seu instinto, pode buscar e recolher. Outros acreditam que as abelhas, com preparo e ordenação, convertem em mel aquilo que retiram dos mais tenros botões e das flores, não sem algum - por assim dizer - fermento, por meio do qual fundem diversos elementos em um único" (PETRARCA apud MORGANTI, 2017, p. 217).

7 Sobre a noção de gênio original e a desconsideração das operações engenhosas e inventivas dos processos miméticos, observe-se, por exemplo: (ADORNO, 1970). Sobre a característica essencial do gênio ser a "originalidade", a partir de uma produção não imitativa nem de artistas nem da natureza, que não pode ser ensinada nem aprendida, ver: (KANT, 2012). Valer observar a emergência da Estética como disciplina filosófica em meados do século XVIII, ligada a Alexander Baumgarten que a apresentou como uma tentativa de organização que buscaria unificar as regras esparsas da beleza em uma ciência sistemática. A novidade da estética moderna seria a abordagem científica de matéria já bem conhecida: as normas da representação artística e do bom gosto expostas, desde a antiguidade, por Aristóteles, Horácio, Cícero, Quintiliano e Longino. O projeto 
O século XVIII foi marcado pela consolidação e a emergência de dinâmicas políticas, sociais, econômicas, culturais e históricas que redefiniram a compreensão e as ações humanas sobre a sociedade e a natureza na Europa, com impactos contundentes que foram decisivos para a inflexão histórica que se nomeia como modernidade. Naquela conjuntura, no movimento iluminista alemão - o movimento do Esclarecimento, o Aufklärung - emergiu o conceito moderno de Bildung, o qual, em sua alta complexidade, reverberava e abrangia campos como a pedagogia, a educação, a cultura, qualificando debates sobre o que seja o humano e a humanidade, sobre a sociedade e o Estado (BOLLE, 1996, p. 14), guardando interações críticas, portanto, nos âmbitos da ética e da estética.

Até meados daquele século, Bildung era empregada no sentido calcado sobre a noção latina de "imagem" oriunda do termo latino imago e do alemão Bild - forma, figura, imagem -, ressoando a herança medieval e expressando a ideia de uma reprodução por semelhança, a imitatio latina, em alemão Nachbildung. Com flagrante conotação artística, prevalecia nesse processo mimético um sentido plástico - traduzido também no termo Bildende Künste, artes plásticas. Os verbos alemães bilden e sich bilden designavam a formação de minerais, vegetais e animais, mas não só: eles também, como formação, correspondiam às atividades artísticas dos fazeres reprodutivos e dos representacionais. Essa noção de formação acomodou-se na ambiência do ideário da Aufklärung através de pensadores pietistas, processando a transição semântica de uma Bildung como procedimento que forma e molda coisas para significar a formação de uma experiência interior, mental, psíquica, espiritual (BOLLE, 1996, p. 15-16), portanto, subjetiva.

O movimento Aufklärer utilizou indistintamente durante algum tempo os termos Bildung (formação) e Erziehung(educação), exprimindo, na predominância do segundo, a ênfase na tendência de sua "vontade de ensinar", aprendida com Rousseau. Por certo, no "imperativo categórico" de Kant e ao longo de sua obra a capacidade de aprender fora determinante para definir o teor do propriamente humano, caracterizado pelo desenvolvimento gradual da razão, impulsionando, enfim, o fomento dessa vontade de ensinar (KANT, 1985; KANT, 2004; KANT, 2006; KANT, 2010).

$\mathrm{Na}$ sociedade alemã do período, a formação adequada deveria tornar as pessoas úteis ao sistema econômico e ao bem-estar social, acentuando-se os aspectos pragmáticos em vista da satisfação dos interesses do Estado. Os esestritamente lógica (PRANCHÈRE, 1988; BAUMGARTEN, 1993). 
tados alemães passaram a investir maciçamente na organização de um sistema escolar público, visando o ensino primário, nas décadas finais do século XVIII (BOLLE, 1996, p. 16). Esse sentido pragmático influenciou, ainda, o concurso para definir o projeto da Universidade de Berlim nas primeiras décadas do século XIX, vencido por Schleiermacher (FICHTE, 1999; CASPER \& HUMBOLDT, 2003).

A ideia de Bildung, contudo, não poderia ser desenvolvida pela educação restrita à ensinança, exigindo "liberdade" e "autonomia", efetuando-se como autodesenvolvimento. Bildung, nesse sentido, operaria como corretivo da educação. Com o pensamento kantiano e com o de Herder, especialmente, foi que o conceito de Bildung não apenas se distanciou da noção de educação como ensinança, mas opôs-se a ela, pondo em jogo o cuidado, o desenvolvimento e o desabrochar das energias psíquicas e do bom gosto. Herder opôs Bildung à educação e ao ensino, valorizando-a em detrimento desses, destacando as qualidades da "autoformação" e da "atuação viva" não apenas de indivíduos, mas de povos inteiros e da própria humanidade (BOLLE, 1996, p. 17).

No contexto do classicismo, do romantismo e do idealismo alemão, Bildung ultrapassou as noções de educação, progresso e mesmo esclarecimento. Segundo Herder, Bildung seria o conceito crucial para todos que estivessem empenhados no desenvolvimento físico, psíquico e intelectual do ser humano, oferecendo consistência às noções de "espírito", "cultura" e "humanidade". A própria modernidade poderia ser considerada, então, "os tempos da formação", Zeiten der Bildung, sendo os indivíduos tratados em seu desenvolvimento espiritual e ético em analogia com o caminhar da humanidade em uma filosofia da história atinente à formação da espécie humana.

Nesta circunscrição argumentativa, vale especular sobre a etimologia da palavra mimesis, observando que nela se guarda, nuclearmente, a noção daquilo que se forma e aparece - por vezes, como algo que não necessariamente é o que parece ser. A origem do termo mim- em grego, entretanto, não é possível recobrir, sendo ela obscura e substancialmente ignorada (HALLIWELL, 2002, p. 17; DI SANTO, 2016, p. 27). Di Santo, porém, indica que a extensão semântica da palavra sânscrita maya implica contatos significativos com o termo, quando abrange: arte, sabedoria, decepção, fraude, truque, feitiçaria, imagem irreal ou ilusória, fantasma, aparição. Em sânscrito haveria o radical $m a$ - que se alterna com $m i$-, cujo significado de base seria medir, mas que significaria também: preparar, arranjar, criar, formar, construir, fazer, além de mostrar, exibir, demonstrar, compor. O exemplo a que recorre o dicionário utilizado por Di Santo foi 
retirado do Rig-Veda e ele o acha interessantíssimo por apontar para "as várias formas que o deus assume" (DI SANTO, 2016, p. 27-28).

No exemplo, Di Santo destacou o termo ámimita - no grego, emimeito - indicando a tradução do sânscrito para o inglês que o significou como "ele demonstrou-se ou desenvolveu-se", o qual predisporia a ideia de "se mostrar na forma de", "assumir a aparência de"; no caso, a forma da mãe como avatara do deus, isto é, como a aparência assumida pela divindade que descende à terra. Di Santo indica ainda que, de outro modo, o termo seria da mesma raiz, ao que parece, do substantivo maya - imagem ilusória - como também do adjetivo maya - comparação que cria ilusões -, em uma formação que pareceria com o sufixo grego mimos. Em todo caso, afirma ele, "o paralelo de uma raiz que apresenta o grau zero $m i$ - associado ao significado de 'mostrar-se', 'assumir a aparência de' parece muito relevante como possível étimo de mimesis" (DI SANTO, 2016, p. 27-28). Di Santo argumenta que se essa etimologia for correta a ideia de fundo da família mimos, mimeomai, mimesis estaria conectada não tanto com a ideia de "imagem", quanto com a ideia de "imitar a aparência", imitar a forma exterior e sensível, em processo em que é sublinhado o caráter artificial e ilusório, até mesmo enganoso (DI SANTO, 2016, p. 32).

Em lugar de uma conclusão, fica a ponderação de que a compreensão sobre a complexidade e a abrangência das relações entre mimese e educação pode oferecer parâmetros e critérios, ao mesmo tempo, amplos, permeáveis e lúcidos o suficiente para sustentar uma visada crítica razoável e consistente sobre dinâmicas formativas brasileiras como, por exemplo, as que forjaram representações luso-brasileiras no período da "política católica" com categorias estético-políticas durante a colonização ibérica na América portuguesa (HANSEN, 2001, p. 11) ${ }^{9}$. Desse modo, favorecendo uma interpretação crítica que

8 Reproduzo o exemplo citado: "As Germ Celestial he is called Tanunapat, and Narasamsa born difused in varied form./Formed [ámimita] in his Mother he is Matarisvan; he hath, in his course, become the rapid flight of wind" (MONIER-WILLIAMS apud DI SANTO, 2016, p. 28); o grifo é de Di Santo. Tradução livre "Como Germe Celestial ele é chamado Tanunapat e Narasamsa nasce difundido em forma variada./ Formado [ámimita] em sua Mãe ele é Matarisvan; ele tem, em seu curso, transformar-se no rápido voo do vento".

9 Como aprendemos com João Adolfo Hansen, na sociedade brasileira do século XVII a identidade era definida como representação e pela representação em uma "ocasião de sua aplicação como aparência decorosa subordinada no corpo místico do Império Português". A expressão "século XVII", por seu turno, sendo utilizada para classificar a duração da "política católica" da colonização ibérica anti-maquiavélica e anti-luterana com extensões diversas que coexistem. Algumas aparecem como "longuíssimas durações de referências e modelos gregos, latinos, patrísticos, escolásticos, neo-escolásticos", os quais desaparecem no final do século XVII, outras durações que continuaram se desdobrando como os "modelos artísticos italianos e ibéricos quinhentistas e seiscentistas aplicados na arquitetura, na escultura e na pintura do final do século XVII e início do século XIX". 
reconheça a circunscrição histórica que resiste às variáveis heurísticas instruídas pela modernidade iluminista-romântica de um período ainda pouco explorado pela historiografia brasileira - e, menos ainda, pela historiografia da educação brasileira - e que não operava segundo as categorias que emergiam então.

Sugiro, ainda, que observar o processo mimético como dinâmica de tensionamento das fronteiras aparentes entre conhecimento, filosofia, saber científico e técnico e aquilo que se designa como poiesis, criação, arte e representação pode incrementar um olhar epistêmico mais vigoroso sobre as condições de contorno dos referenciais que constroem o exercício intelectual poligráfico de escritores e artistas, as quais, no mais das vezes, subtraem-se à reflexão, sendo ocultas ou elipsadas, tornando-as irrefletidas. Elucidar os processos pelos quais as tendências de pensamento prevalentes em representações e modelos emergem na interface entre conhecimento e representação evitaria a adesão que não se interrogue criticamente sobre seus fundamentos e que se partilhe como evidência convencionada, manifestando o ponto cego do pensamento crítico em que se aninham prejuízos hermenêuticos. Nesse sentido, remontar à gênese histórica do conceito de mimese e mesmo à sua etimologia pode ser um modo para fazer uma crítica social e cultural do presente através do passado.

\section{REFERÊNCIAS}

ADORNO, T. W. Teoria Estética. Lisboa: Edições 70, 1970.

ARISTÓTELES. Poética. Coimbra: Fundação Calouste Gulbenkian, 2007.

BAKTIR, H. "The concept of imitation in Plato and Aristotle". Sosyal Bilimler Enstitüsü Sayt, n. 15, p. 167-179, 2003.

BASTOS, R. A. "Regularidade e ordem das povoações mineiras no século XVIII". Revista do IEB-USP, São Paulo, n. 44, p. 27-54, fev. 2007.

BAUMGARTEN, A. G. Estética: a lógica da arte e do poema. Petrópolis: Vozes, 1993.

BOLLE, W. "A ideia de formação na modernidade". GHIRALDELLI Jr., P. Infância, escola e modernidade. São Paulo; Curitiba: Cortez; Ed. UFPR, 2007. p. 9-32.

CASPER, G. \& HUMBOLDT, W. Um mundo sem universidades? Rio de Janeiro: EdUerj, 2003.

COLE, T. The origins of rhetoric in ancient Greece. Baltimore: Johns Hopkins University Press, 1995. 
CONTE, G. B. The rhetoric of imitation. Genre and poetic memory in Virgil and other Latin poets. Ithaca: Cornell University Press, 1996.

DI SANTO, F. Genealogia dela mimesis: fra mimesis antica e imitatio rinascimentale. Bologna: ETS, 2016.

FICHTE, J. G. Por uma universidade orgânica. Rio de Janeiro: EdUerj,1999.

GUINSBURG, J. A república de Platão. São Paulo: Perspectiva, 2006.

HANSEN, J. A. "Barroco, neo-barroco e outras ruínas”. Teresa, n. 2, p. 10-66, 2001.

HALLIWELL, S. The aesthetics of mimesis: ancient texts and modern problems. Princeton: Princeton University Press, 2002.

HORÁCIO. Arte poética. Lisboa: Editorial Inquérito, 1984.

ISER, W. “O ressurgimento da estética”. ROSENFIELD, D. L. (org). Ética e estética. Rio de Janeiro: Jorge Zahar, 2001. p. 35-49.

KANT, I. Começo conjectural da história humana. São Paulo: Ed. Unesp, 2010.

KANT, I. Crítica da faculdade do juízo. Rio de Janeiro: Forense Universitária, 2012.

KANT, I. Ideia de uma história universal de um ponto de vista cosmopolita. São Paulo: Martins Fontes, 2004.

KANT, I. "Resposta à pergunta: o que é "Esclarecimento"? (Aufklärung)". In: Textos seletos. Petrópolis: Vozes, 1985. p. 100-117.

KANT, I. Sobre a pedagogia. Piracicaba: Unimep, 2006.

KENNEDY, G. A. A new history of classical rhetoric. Princeton: Princeton University Press, 1994.

KENNEDY, G. A. Classical rhetoric and its Christian and secular tradition from ancient to modern times. Carolina do Norte: The University North Carolina Press, 1999.

LEE, R. W. "Ut pictura poesis: the humanistic theory of painting”. Art Bulletin, v. 22, n. 4, p. 197-269, decembrer 1940.

LOPES, D. R. N. "Estudo introdutório: A moralidade da estética platônica na República". Platão: a república - livro $X$ - tradução, ensaio e comentário crítico. Dissertação de Mestrado (Instituto de Estudos da Linguagem), Unicamp, Campinas, 2002. p. 6-30.

MORGANTI, B. “As imagens da imitação em Petrarca”. RAGAZZI, A.; MENESES, P. D.; QUÍRICO, T. (orgs.). Ensaios interdisciplinares sobre o renascimento italiano. São Paulo: Editora Unifesp, 2017. p. 209-230.

PRANCHÈRE, J. “L'invention de l'esthétique”. BAUMGARTEN, A. G. Esthétique, précédée des Méditations philosophiques sur quelques sujets se rapportant à l'essence du poème et de la Métaphysique (\$\$ 501 à 623). Paris: L'Herne, 1988. 
PRATA, P. O caráter alusivo dos Tristes de Ovídio: uma leitura intertextual do livro I. Dissertação de Mestrado (Instituto de Estudos da Linguagem), Unicamp, Campinas, 2002.

PRATA, P. O caráter intertextual dos Tristes de Ovídio: uma leitura dos elementos épicos virgilianos. Tese de Doutorado (Instituto de Estudos da Linguagem), Unicamp, Campinas, 2007.

RICOEUR, P. Tempo e narrativa - 3 v. São Paulo: Martins Fontes, 2010.

RUSSEL, D. A. “De imitatione". WEST, D. \& WOODMAN, T. Creative imitation and Latin literature. Cambridge: Cambridge University Press, 2001. p. 1-16.

SELIGMANN-SILVA, M. "Introdução/Intradução": mimesis, tradução, enárgeia e a tradição da ut pictura poesis. In: LESSING, Gothold E. Laocoonte ou sobre as fronteiras da pintura e da poesia. São Paulo: Iluminuras, 1998. p. 7-72.

Texto recebido em 11 de novembro de 2018.

Texto aprovado em 14 de dezembro de 2018. 